University of Denver

Digital Commons @ DU

University Libraries: Faculty Scholarship

University Libraries

Summer 2014

\title{
Utilizing Building Usage Assessment: Determining Deployment of Student Workers in an Academic Library
}

Ryan F. Buller

University of Denver

Follow this and additional works at: https://digitalcommons.du.edu/libraries_facpub

Part of the Library and Information Science Commons

\section{Recommended Citation}

Buller, Ryan F. "Utilizing Building Usage Assessment: Determining Deployment of Student Workers in an Academic Library." Journal of Access Services 11.3 (Summer 2014): 109-118.

This Article is brought to you for free and open access by the University Libraries at Digital Commons @ DU. It has been accepted for inclusion in University Libraries: Faculty Scholarship by an authorized administrator of Digital Commons@DU. For more information, please contact jennifer.cox@du.edu,dig-commons@du.edu. 


\section{Utilizing Building Usage Assessment: Determining Deployment of Student Workers in an Academic Library}

\section{Publication Statement}

Copyright held by the author or publisher. User is responsible for all copyright compliance. 
Running head: ASSESSING BUILDING USAGE FOR STUDENT WORKER DEPLOYMENT

Utilizing Building Usage Assessment:

Determining Deployment of Student Workers in an Academic Library

Ryan F. Buller

Western Illinois University

Author Note

Ryan F. Buller, University Libraries-Access Services Unit, Western Illinois University.

Ryan F. Buller is now at University Libraries-Access Services Team, University of

Denver.

Data in this paper is used and presented with permission of Felix Chu, Associate Dean of University Libraries, Western Illinois University.

Correspondence concerning this article should be addressed to Ryan Buller, Anderson Academic Commons \#220F, 2130 E Evans Ave., Denver, CO 80208. E-mail:

Ryan.Buller@du.edu 
Running head: ASSESSING BUILDING USAGE FOR STUDENT WORKER DEPLOYMENT

\begin{abstract}
Generating, collecting, and analyzing building usage statistics can greatly increase the ability of an Access Services Unit to meet the changing dynamic of patron needs in an academic library. By analyzing three different data points, the Access Services Unit in Malpass Library at Western Illinois University was able to determine the most effective and efficient way to deploy the student workforce to meet the demonstrated needs of the patron population throughout the day. This article will examine those data points and how they were analyzed in order to improve the services provided by the Access Services Unit.
\end{abstract}


Running head: ASSESSING BUILDING USAGE FOR STUDENT WORKER DEPLOYMENT

\section{Utilizing Building Usage Assessment:}

Determining Deployment of Student Workers in an Academic Library

\section{INTRODUCTION}

The ability to generate, collect, and analyze data is a fundamental strength of academic libraries, especially in an Access Services Unit. The majority of data that is collected is good for comparing changes and trends over the course of time. Public service personnel need to develop better ways of collecting and analyzing usage statistics in order to provide more effective and efficient services, especially through the use of student workers. The Access Services Unit in Malpass Library at Western Illinois University devised a way of maintaining certain data sets that allowed for a determination of when people were coming into the library, what they were doing while they were in the library, and how best to utilize the workforce of student workers in order to meet the changing needs of patrons throughout the day. This paper will look

specifically at how the Access Services Unit at Western Illinois University used this data in order to determine the workflow of student workers within the unit.

\section{LITERATURE REVIEW}

There is a healthy amount of literature regarding the use of data to aid in decision making within libraries. While not within the Access Services Unit, J. Eric Davies, the Director of The Library and Information Studies Unit at Loughborough University, looked at Evidence Based Management within the context of the library as a whole. Davies (2002) wrote "The 
Running head: ASSESSING BUILDING USAGE FOR STUDENT WORKER DEPLOYMENT

more transparent the style of managing with evidence, the better understood and shared will be service aims and objectives and the greater the capacity for decision making and operational refinement throughout an organization." Here, Davies showed the importance of analyzing data within the library setting, tying staff buy-in of decision making by management to transparency of decisions based on evidence. Looking at this within the context of the Access Services Unit with regards to this paper, staff and student workers will understand staffing needs and assignments when decisions are based on an analysis of the maintained statistics, and they can see and engage with that analysis for themselves.

The use of data to determine staffing levels at public service desks, both reference and lending, is a very popular topic in library literature. In regards to reference, Gerlich and Whatley (2009) used the READ Scale to gather data and assess staffing levels and needs at the reference desk. Todorinova, Huse, Lewis, and Torrence (2011) similarly used a task force to assess electronic data collection to drive a recommendation for staffing levels of a new reference desk model. Within Access Services, Weaver-Meyers, Aldrich, and Seal (1985) collected data to determine the cost of various services through the Access desk. The data was used to revise work assignments and staff scheduling. Finally, Sewell and Alarid (2013) collected data to determine staffing levels at a circulation desk for staff and student workers resulting in a layered staffing model. While slightly different in terms of aim, these resources all provide excellent examples in the collection and analysis of data to drive decision making in libraries as it relates to staffing at public service desks.

Another excellent example of analyzing data within Access Services was presented when examining the Access Services Unit at the University of Montana. Brown(2010) examined data 
Running head: ASSESSING BUILDING USAGE FOR STUDENT WORKER DEPLOYMENT

that "helped identify and guide management priorities and resource requests," over long periods of time. Brown presents the changing nature of the Access Services Unit at the University of Montana over the last 20 years, and how that data was used to not only determine staffing levels and workflow, but changes to the overall structure of the Access Services Unit over time.

There is significantly less literature when it comes to data analysis for day-to-day operations in an Access Services Unit away from the service desk. Tolpannen(2004) found in his study that $94.6 \%$ of Access Services Units reported recording statistics as a task currently performed at their institution. This finding indicates that most institutions are actively engaged in generating and collecting data for statistical analysis. This creates a scenario where institutions may be collecting data that can be utilized in different ways than it was originally intended in order to help drive decision making within this area.

\section{BACKGROUND}

The need to approach this problem resulted from a skewed distribution regarding staff involvement in directing student workers throughout the day. This resulted in a situation that placed an additional burden on the two night staff, both of whom were then responsible for making sure that student workers completed more work than their counterparts during the day. This responsibility was added to their individual staff duties of database development and overdue correspondence in addition to backing up the interlibrary loan and reserve staff. This affected staff ability to complete their required primary job responsibilities in a timely manner while simultaneously being in charge of patron interactions at the lending desk and responding to problems throughout the six story library. 
Running head: ASSESSING BUILDING USAGE FOR STUDENT WORKER DEPLOYMENT

Additionally, the moral of student workers was declining. Student workers during the day were disappointed that their duties appeared to be arbitrarily assigned. Student workers during the evening felt overburdened and that the day time student workers were not doing their fair share. The decision was made to approach the issue regarding the distribution of workflow for student workers in a timely manner by providing direction regarding the types of work that should be done at the various times of the day. The staffing levels for student workers throughout the week had been determined by the previous unit coordinator by assessing day-today and hour-to-hour variations of patron levels throughout the week. The new unit coordinator wanted to approach the problem as quickly as possible to help ease staff and student worker tensions during a time of transition.

The ability to approach this issue in a timely manner was aided by the data collection that was already taking place within the Access Services Unit. All of the data types presented in this paper were already being collected and maintained within the Access Services Unit for reporting to different units in the library, as well as on the annual report. There were both positive and negative aspects to this approach. On the positive side, the process of collecting the data was already established in the daily workflow for staff and student workers. This allowed for work to continue as normal while the problem was being addressed. It also allowed a quicker turn-around regarding the analysis of the data and for changes to be implemented, as there was no need to wait for the data to be collected over a long period of time in order to determine trends and notice variations.

The speed with which the problem was addressed also resulted in negative, or less than optimal, aspects. A more deliberate approach would have potentially allowed for a more 
Running head: ASSESSING BUILDING USAGE FOR STUDENT WORKER DEPLOYMENT

comprehensive look at building usage. Further, a more deliberate approach would have potentially yielded a better structure for collecting and maintaining the data, as opposed to collating data from different areas for the analysis. Finally, approaching the problem quickly resulted in the need to reexamine the data every month in order to determine changes in trends. A better laid out plan may have resulted in a situation where the data could be reanalyzed on a quarterly or yearly basis in order to determine changes in trends, as opposed to monthly.

\section{DATA TYPES}

Before looking at the specific data types, it is important to note that these types of statistics are largely due to the specific layout of Malpass Library. The library itself is six stories, encompassing 200,000 square feet. The library has an open atrium in the middle, extending from the first floor to the sixth floor. The top three floors are divided into four separate wings circling the open atrium. The bottom three floors do not circle the entire atrium, as space for entrances/exits, staff workspace, and storage space is accommodated on these floors. The library has three separate entrances that funnel into the second floor atrium. There is a security gate in the atrium that everyone must pass through to gain entrance into the library. The physical structure of the building allows for a dedicated position to keep track of people entering into the building through the security gate. Additionally, the layout of each floor made it easy to create sections based on resources in those physical locations, allowing library staff to see how many people are in each section of the library and to understand what resources they are using.

\section{Desk Patron Count}


Running head: ASSESSING BUILDING USAGE FOR STUDENT WORKER DEPLOYMENT

The Desk Patron Count is a hand count of all patrons that come through the security gates on the second floor of the atrium. This provides a count of how many patrons are entering Malpass Library every hour that the library is open. This count differs from a traditional gate count maintained by an electronic security gate/patron counter in a few key ways. First, the traditional count utilizing a security gate does not distinguish library employees from patrons. Further, the traditional gate counter would count people who have been in the library, left briefly (smoking, using a bathroom on the other side of the security gate, etc.) and then re-entered the library. Having a hand count allows the Access Services Unit to have a clear picture of how many patrons are coming into the library, and when they are coming in. Maintaining the Desk Patron Count at the atrium desk helps to keep the student or staff member manning the desk alert and engaged. It also ensures that patrons are being acknowledged when they enter and exit the building, leading to more attentive customer service.

\section{Area Patron Count}

The Area Patron Count is a count of all patrons within Malpass Library at a given time. The count is conducted by a student worker every hour. The count is broken down by section and floor. The purpose of the count is to see what resources patrons are using within the building, and when they are using them. A very nice benefit of the Area Patron Count is that it allows the Access Services Unit to maintain a consistent presence throughout the six story library. This allows student workers to notify staff of any problems that are encountered, such as noise complaints/disruptive behavior, problem areas in the stacks, technology issues (printers, network, or hardware), and the general appearance of the building. This allows the Access Services Unit to be proactive in addressing issues and concerns. 
Running head: ASSESSING BUILDING USAGE FOR STUDENT WORKER DEPLOYMENT

\section{Average Transactions}

The transactions statistics are not a count in the sense of the other two counts being offered here. Rather, this data comes from a query written by the Library Systems Unit of Malpass Library that pulls information from the integrated library system (ILS). The information presented in this report includes the number of transactions by day and hour, as well as the average number of transactions by hour over a certain timeframe. The information is broken down by transactions for the main collection and reserve collection. For simplicity, these counts are added together to give a better understanding of desk activity, as both collections circulate from the main Access Services desk.

\section{UTILIZING STATISTICS}

Generating and collecting data for usage statistics was one part of the process. Analysis of the statistics in a meaningful way was imperative to addressing how to deploy student workers throughout the day. For the purpose of this article, a comparison of the hourly averages of the three previously discussed statistical counts for the month of September, 2012 will be conducted. This comparison is being done to illustrate how decisions were made to determine how to best leverage student workers throughout the day to provide efficient, effective, and proactive service to library patrons. It does not necessarily reflect the actual results of the analysis that was implemented at Malpass Library, and is being used as an example for managers and supervisors that may be new to their positions and struggling to determine how best to use personnel resources. This is far from an exhaustive comparison; it is merely the tip of the iceberg. For example, it does not take into account day-to-day variations of patron levels that would be 
Running head: ASSESSING BUILDING USAGE FOR STUDENT WORKER DEPLOYMENT

necessary to appropriately determine staffing levels of student workers. Rather, it focuses on how best to use the student workers once they are in the building. See Table 1 for a comparison of hourly average counts for the remaining paragraphs of this section.

The average floor count by hour is calculated by taking the sum total of the count for all sections of the library on an hourly basis, then dividing by the number of days. When looking at the average floor count for September, 2012, a few key trends emerge. First, the average floor count by hour increases rapidly until the 10 a.m. count. At this point, the average count fluctuates between 110 and 130 patrons per hour. The count then increases each hour until peaking at 266 patrons per hour at 8 p.m. There is a slight decline on the 9 p.m. floor count, and then more substantial declines for the 10 p.m. and 11 p.m. floor counts.

The average gate count by hour is calculated by taking the sum total of the count by hour for all days, divided by the total number of days. When looking at the average gate count for September, 2012, we see a very steady number of patrons entering the library. The count grows from 82 patrons per hour at 8 a.m. to 102 patrons per hour at 9 a.m. The average patrons-perhour count fluctuates between 100 and 120 patrons per hour until 4 p.m. The numbers dip for the 4 p.m. to 6 p.m. counts. The count peaks at 111 patrons per hour for the 7 p.m. count, then steadily decreases each hour until the library closes.

The average transactions per hour were taken directly from a report produced by the Library Systems Unit. The report presents the transactions for main circulation and reserve circulation as two separate entities. For the purpose of this analysis, the counts have been combined to represent all transactions taking place at the Access Services desk. The average 
Running head: ASSESSING BUILDING USAGE FOR STUDENT WORKER DEPLOYMENT

transactions start high with over 10 transactions during the 8 a.m. hour. The count then drops to 7.5 transactions during the 9 a.m. hour, increasing slightly until the 1 p.m. hour. The count jumps during the 2 p.m. hour to over 12.75 transactions per hour. The 3 p.m. hour is also high with over 11.75 transactions per hour. The transactions then fluctuate for the remainder of the day between 4.77 transactions per hour and 9.91 transactions per hour.

Now that each count has been looked at individually, it is necessary to look at them together in order to get a clear picture. When examining the average floor count and the average gate count, two main trends emerge. From 9 a.m. to 3 p.m. the average gate count remains high, between 100 and 120 patrons per hour. Over the same period of time, the average floor count remains consistent. This indicates that while a number of people are entering the library every hour, they are not staying in the library for long periods of time. If they were, the average floor count each hour would be increasing due to the amount of foot traffic entering the building. To contrast, even though the number of people entering the building declines after 4 p.m. (with the exception of the spike at 7 p.m.) the average floor count continues to rise, peaking at 8 p.m. This means that while not as many people are entering, the library patrons are staying in the building longer.

This gives a good picture regarding turnover of library patrons by comparing average floor count to average gate count. When adding in the average transactions per hour, we are able to get a good idea of what people are using when turnover is higher in the library. The two most popular activities for library patrons when coming into the library for a short period of time are to print something for class or to check out material. Patrons who are doing research based activities or studying would be in the library for a longer period of time, and generally, counted 
Running head: ASSESSING BUILDING USAGE FOR STUDENT WORKER DEPLOYMENT

on the hourly floor count. As the average number of transactions per hour stays lower from 9 a.m. to 1 p.m. it is realistic to conclude that more people are coming into the library to print materials out for class. Conversely, the higher average transactions for the 2 p.m. and 3 p.m. counts indicate that more patrons are coming into the library to check out material. As was previously noted, patrons stay in the building longer as the day progresses into evening. That coupled with the fluctuating average transaction counts indicate that while there are more patrons in the building, checking out library material is not the motivating factor for being in the library.

Now that patron uses and behaviors have been established by looking at the three counts, it is important translate this into providing effective, efficient service. Libraries are frequently facing situations where they are expected to provide more services with fewer resources at their disposal. One way to provide better services in this situation is to base unit workflow on the analysis of the data. In the case of this example, student workers would be deployed to different areas of the library based on the observed user patterns.

During the morning, when the library has higher patron turnover, but the number of average transactions is lower, in addition to their normal duties, student workers would be used to walk through computer labs, checking paper levels in printers, toner levels, ensuring that the staplers are full, and identifying patrons that need assistance troubleshooting technical problems. This will result in fewer issues and complaints for patrons using computers in the library. Conversely, when patron turnover is high and there is a spike in average transactions during the mid-afternoon, an extra student worker should be kept near the desk to aid staff in checking out material. This will result in lower wait times for patrons at the circulation desk, thereby proactively meeting the demonstrated needs of patrons. Finally, the higher average floor count 
Running head: ASSESSING BUILDING USAGE FOR STUDENT WORKER DEPLOYMENT

and lower average gate count in the late afternoons and evenings indicate that people are staying in the library longer at these times. The fluctuating average transactions do not indicate a need to keep an extra student worker at the Access Services desk. Instead, there is a greater need for a library presence throughout the 6 floors of Malpass Library. During this time of day student workers could be used to shelve material, conduct pickups, and search for material for interlibrary loan requests. Students would work on duties that allow the unit to maintain a visible presence throughout the library. This visible presence allows the Access Services Unit to keep abreast of what is going on in the building. This will allow staff members to respond quickly, and proactively, to issues that may arise.

\section{RESULTS}

Engaging in an analysis of building usage data resulted in multiple benefits for the Access Services Unit at Malpass Library. First, it allowed the Access Services staff to better understand how the building was being used. This resulted in pressure being taken off of Access Services staff to appropriately deploy the student worker workforce. Instead, the workflow throughout the day was predetermined based on the analysis of the data points leading to more meaningful work for the student workers. Second, student workers were better able to understand the duties they were being assigned. They no longer felt that job duties were arbitrarily assigned as they could see the reasoning behind the assigned duties. This resulted in higher job satisfaction as student workers were more engaged in their jobs. Finally, the Access Services staff and student workers were better able to meet the changing needs of patrons throughout the day by altering how student workers were deployed. This resulted in higher patron satisfaction as their needs were being preemptively met by Access Services staff and 
Running head: ASSESSING BUILDING USAGE FOR STUDENT WORKER DEPLOYMENT

student workers. Overall, switching to deploying student workers based on the analysis of the three data points resulted in multiple benefits for the Access Services Unit at Malpass Library.

\section{CONCLUSION}

Public service desks are frequently being asked to take on additional roles and responsibilities, often while facing difficult financial constraints. Carefully creating, maintaining, and analyzing usage statistics can help Access Services Units to distribute front-line student resources appropriately, thereby proactively meeting the demonstrated needs of patrons. The example provided here illustrates one way of approaching the collection and analysis of data in order to use personnel resources in an effective and efficient manner. By comparing the average floor count, gate count, and transaction count on an hourly basis, the Access Services Unit in Malpass Library at Western Illinois University was able to appropriately deploy the workforce of student workers to address the changing nature of patron needs throughout the day. This allowed the Access Services Unit to be proactive in meeting the needs of patrons, resulting in higher patron satisfaction and better overall customer service. 


\section{REFERENCES}

Brown, B. N. (2010). Access Services Management Measures Revisited: From Triage to Marketing to Disarticulation. Journal of Access Services, 7(2), 84-96. doi: $10.1080 / 15367961003620125$

Davies, E. J. (2002). What Gets Measured, Gets Managed: Statistics and Performance Indicators for Evidence Based Management. Journal of Librarianship and Information Science, 34(3), 129-33. doi: 10.1177/096100060203400301

Gerlich, B.K, \& Whatley, E. (2009). Using the READ Scale for Staffing Strategies: The Georgia College and State University Experience. Library Leadership \& Management, 23(1), 2630. Retrieved from http://journals.tdl.org/llm/index.php/llm/index

Sewell, B. B., \& Alarid, T. (2013). Managing the Access Services Desk: Utilizing Layered Levels of Staff Skills. Journal of Access Services, 10(1), 6-13. doi: 10.1080/15367967.2013.738389

Todorinova, L., Huse, A., Lewis, B., \& Torrence, M. (2011). Making Decisions: Using Electronic Data Collection to Re-Envision Reference Services at the USF Tampa Libraries. Public Services Quarterly, 7(1-2), 34-48. doi: $10.1080 / 15228959.2011 .572780$

Tolppanen, B. P. (2004). A Survey of Current Tasks and Future Trends in Access Services. Journal of Access Services, 2(3), 1-14. doi: 10.1300/J204v02n03_01

Weaver-Meyers, P., Aldrich, D., \& Seal, R. A. (1985). Circulation Service Desk Operations: Costing and Management Data. College and Research Libraries, 46(5), 418-31. Retrieved from http://crl.acrl.org/ 
Running head: ASSESSING BUILDING USAGE FOR STUDENT WORKER DEPLOYMENT

Table 1

Average Paton Counts for September 2012

\begin{tabular}{|c|c|c|c|}
\hline \multicolumn{1}{|c|}{ Time } & Floor Count & Gate Count & Transactions \\
\hline 8:00 AM & 28.32 & 82.80 & 10.58 \\
\hline 9:00 AM & 83.16 & 102.27 & 7.51 \\
\hline 10:00 AM & 110.33 & 117.10 & 8.54 \\
\hline 11:00 AM & 118.75 & 105.37 & 9.28 \\
\hline 12:00 PM & 118.33 & 114.93 & 9.23 \\
\hline 1:00 PM & 111.28 & 119.70 & 9.35 \\
\hline 2:00 PM & 119.41 & 100.40 & 12.77 \\
\hline 3:00 PM & 126.83 & 107.27 & 11.78 \\
\hline 4:00 PM & 129.77 & 91.70 & 8.25 \\
\hline 5:00 PM & 128.45 & 88.07 & 6.43 \\
\hline 6:00 PM & 146.21 & 91.23 & 9.91 \\
\hline 7:00 PM & 199.15 & 111.47 & 6.28 \\
\hline 8:00 PM & 266.05 & 91.43 & 8.90 \\
\hline 9:00 PM & 246.75 & 52.43 & 6.00 \\
\hline 10:00 PM & 180.70 & 21.67 & 4.77 \\
\hline 11:00 PM & 97.05 & 5.27 & 6.42 \\
\hline
\end{tabular}

